\title{
Initiating changes in urology to advance and expand the practice of men's health
}

Neil E. Fleshner, MD, MPH, FRCSC

Professor of Surgery and Martin Barkin Chair of Urology, University of Toronto, Head, Division of Urology, University Health Network, Love Chair in Prostate Cancer Prevention, Princess Margaret Hospital, Toronto, ON

Cite as: Can Urol Assoc J 2014;8(7-8):S141. http://dx.doi.org/10.5489/cuaj.2307

Published online August 11, 2014.

$\mathrm{N}$ early all general male health issues - from depression to cardiovascular disease - have a urologic impact. In many cases, sexual dysfunction is a portal to the early detection of cardiovascular disease, obesity, metabolic syndrome, hypogonadism and bone problems. Urologists therefore have a vital role to play in men's health. By engaging men with a primary urologic complaint, they are well-positioned to communicate important prevention messages, and can play a role in the coordination and collaboration of male health issues from pediatrics to geriatrics. As a gateway to the health system, urologists can help organize standards of care and best practices.

In January 2014, a group of Canadian urologists and other experts with an interest in men's health gathered in Toronto for the Men's Health Summit 2014 to discuss the current state of men's health in Canada, and the role that urologists can play in the overall health of their male patients. This supplement to the Canadian Urological Association Journal summarizes a selection of presentations from this meeting. We hope this series of articles provides you with an awareness of the evolving arena of Men's Health, and the potential role of the urologist as a champion of this field of practice.

Competing interests: Dr. Fleshner is a member of the Advisory Board for Amgen, Janssen, Astellas and Eli Lilly. He has received honoraria from Amgen, Janssen, Astellas and Eli Lilly. He is and has participated in clinical trials for Amgen, Janssen, Medivation, OICR, and Prostate Cancer Canada.

Correspondence: Dr. Neil Fleshner, 610 University Ave., Suite 3-130, Toronto ON M5G 2M9; neil.fleshner@uhn.on.ca 